\title{
Exploring The Interrelations Between Electronic Government And The New Public Management A Managerial Framework For Electronic Government
}

\author{
Kuno Schedler and Maria Christina Scharf \\ Institute for Public Services and Tourism at the University of St. Gallen (Switzerland)
}

\begin{abstract}
This paper explores how electronic government (e-government) can be understood in the context of business administration. Our focus is on nontechnical issues: we concentrate on the analysis of organizational, cultural and managerial aspects, in order to approach the possible development of egovernment and its implications on the public sector at different state levels. Furthermore, we examine the relationship between the Public Management particularly in the form of the New Public Management (NPM) - and egovernment. Based on the outcomes of the analysis mentioned above, an attempt is made to identify the greatest problems that governments will have to face with respect to the introduction of e-government, and what kind of - if any - contribution the disciplines of business administration and NPM can make to resolve these problems. In order to achieve these goals, we set up a conceptual framework for e-government from the perspective of NPM and analyze its components. Our conclusion is that e-government can be interpreted as a reform element that supports the idea behind the NPM and, with its technological equipment, eases modernization as a whole.
\end{abstract}

\section{INTRODUCTION}

Electronic Government (e-government) seems to develop explosively: only a few years ago, the term was virtually unknown even in scientific circles. Today, modernizing the state without e-government is not thinkable any more, both in theory and in practice. However, implementing e-government is not just a technical matter. Experiences with change management in the public sector, deriving from the "New Public Management" reform type, will be of great importance for a successful implementation. 
This paper explores how e-government can be understood in the context of business administration. Our focus is on non-technical issues: we will concentrate on the analysis of organizational, cultural and managerial aspects, in order to approach the possible development of e-government and its implications on the public sector at different state levels. Furthermore, we will examine the relationship between Public Management - particularly in the form of the New Public Management (NPM) - and e-government.

Based on the outcomes of the analysis mentioned above, an attempt will be made to identify the greatest problems that governments will have to face with respect to the introduction of e-government, and what kind of - if any - contribution the disciplines of business administration and NPM can make to resolve these problems. In order to achieve these goals, we will set up a conceptual framework for egovernment from the perspective of NPM and analyze its components.

\subsection{E-Government: A Working Definition}

The term e-government comprises heterogeneous elements and multiple dimensions, and no common definition can be found in the quickly expanding number of publications on e-government. According to the area of expertise, some define e-government as digital information and online transaction services to citizens. Others use the term to refer to electronic commerce, namely online procurement. "At this stage in the evolution of a digital economy and society, "too narrow' a definition can constrain opportunity and 'too broad" a definition dilutes its value as a rallying force" (Caldow 1999).

Public Management primarily sees in e-government the foundation for new forms of communication and - deriving from that - new forms of organization for public institutions and their stakeholders. Therefore, a common definition could be the following:

Electronic Government is a form of organization that integrates the interactions and the interrelations between government and citizens, companies, customers, and public institutions through the application of modern information and communication technologies. ${ }^{70}$

In analogy to e-commerce, e-government can be seen as the sum of new possibilities for public institutions to communicate with others electronically. Various forms of decision-making, business transactions, or simply communication can take place through electronic networks, dramatically changing the way government works.

${ }^{70}$ Source: IDT-HSG Center of Excellence for Electronic Government, http://www.electronicgovernment.org 
Unlike the New Public Management, e-government is not primarily motivated by fiscal stress, administrative and/or political crisis, or dissatisfaction among public managers. Rather, it is a technology-driven reform movement, whereby the reform strategy follows the potential created by modern information and communication technologies (ICT). In this sense, the common phrase "structure follows strategy" will have to be enriched with a further element into: "structure follows strategy follows potential".

While the terms ,governance“ and ,government" are sometimes used interchangeably to depict the same thing, we believe that the two terms bear different meanings, which calls for a brief clarification. The concept of governance generally refers to the task of running a government, or any appropriate entity for that matter. Governance is a broader notion than government ${ }^{71}$. It ,involves interaction between the formal institutions and those in civil society. Governance refers to a process whereby elements in society wield power, authority and influence and enact policies and decisions concerning public life and social upliftment ${ }^{472}$.

\subsection{New Public Management (NPM)}

New Public Management (Hood 1991) has become a widely used term round the world. It describes a global trend of a certain type of administrative reform " ... but it soon becomes apparent [...] that it has different meanings in different administrative contexts" (Ormond and Löffler 1998). For the purpose of this paper, we use the following broad definition: "New Public Management is the generic term for the globally rather uniform ,overall movement" of government reforms. The main characteristic of NPM reforms is the change from input to output orientation" (Schedler and Proeller 2000, p. 5).

\section{A MANAGERIAL FRAMEWORK FOR E- GOVERNMENT}

In this section, we will set up a framework for e-government from the perspective of NPM. We will start by introducing three process elements which, taken together, represent the core processes of a public sector organization. We then will embed the core processes in their cultural context, attempting to define the required elements of a specific "e-government culture". Last, we will discuss the possible contributions of three management techniques to the functioning of e-

${ }^{71}$ E-government is situated in a modern governance concept; the "Digital Era Governance" (Tapscott 1997). Gisler (2001, p. 18) defines "E-Governance" as the design of the general framework for the information society.

${ }^{72}$ Working definition of the British Council. 
government and demonstrate that e-government needs a visionary top-down strategy in order to be successful.

\subsection{Process Elements}

The main aim of e-government is to improve the internal and external performance of the public sector. E-government is based on the changes which were initiated by the New Public Management: a consistent orientation of the public institutions towards the service recipients.

Many terms are too broadly defined when they come up and can therefore be linked to a vast spectrum of contents. This is what is happening with e-government, which will lead to a devaluation of the term in the long run. To counteract this development, a comprehensible as well as useful criterion needs to be employed for designing an e-government concept. The political ,decision-making and production process" could be such a design pattern. The latter can be divided into three axiomatic process steps, each of them being supported by an own e-government module: Electronic Democracy and Participation (eDP), Electronic Production Networks (ePN), and Electronic Public Services (ePS).

\subsubsection{Electronic Democracy and Participation (eDP)}

Electronic Democracy and Participation (eDP) stands for political opinionbuilding and decision-making via electronic media. Examples include Internet voting (e-voting) and citizen networks.

E-voting addresses an important democratic element, the direct participation of the people in the political process. The fact itself is not revolutionary: new forms of voting were introduced before. By and by, those new forms loosened the ties with respect to time and place of a poll (cf. fig. 1). In times when voting was done orally, the introduction of the ballot brought along a certain degree of temporal independence. The absentee vote lifted the local restrictions: instead of having to betake oneself to the ballot, a citizen may cast his or her vote at any mailbox. Evoting will make it even easier to cast a vote by switching from the medium ,paper“ to the medium ,internet“ (or subsequent media). In this context, Korac-Kakabadse and Korac-Kakabadse (1999, p. 212) link specific information technologies (in the broadest sense of the term) with particular political processes and forms:

- orality to democracy and the city-state;

- print to bureaucracy and the nation-state;

- the emergence of the Internet, or the global information infrastructure, to models of e-democracy. 


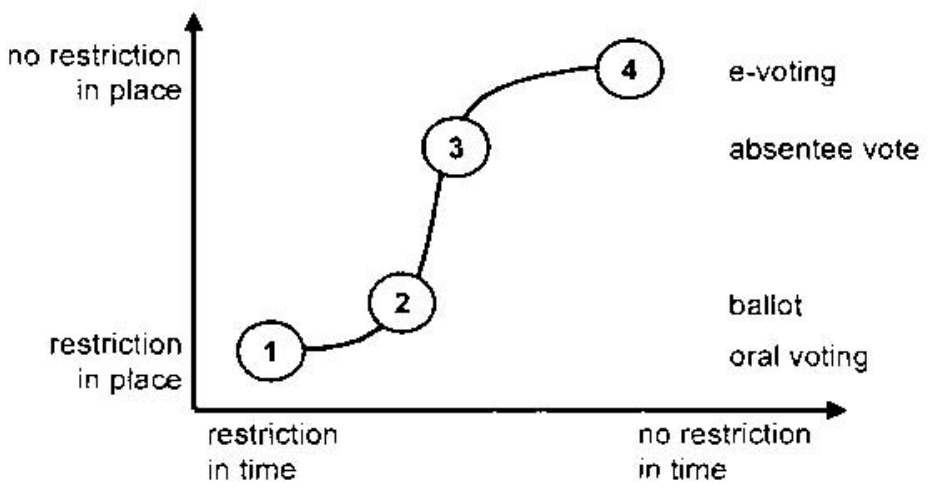

Figure 1. E-voting - decreasing restrictions in time and place

\subsubsection{Electronic Production Networks (ePN)}

Electronic Production Networks (ePN) are forms of co-operation between public and private institutions or between public and public institutions via electronic media. A great potential lies in the setup and maintenance of virtual production networks for fulfilling public responsibilities. The linking-up of different state levels, such as regional extranets with data links for all municipalities, seems particularly worth mentioning. Examples include outsourcing document renewals and e-procurement solutions.

A distinguishing feature of production networks is the fact that different institutions work at the same product in geographically different locations. Economies of scale can be obtained by standardizing processes and by amalgamating administrative activities - a characteristic that Schuh and Strack (1997) also attribute to the virtual factory. In terms of the organization this means that parts of the existing organization need to be split up or segmented in order to be virtually integrated into an optimally configured unit of the production network. At the same time, other parts of external organizations are pooled in the virtual network in view of the task to be accomplished. First successful solutions of this kind have been implemented: An example is given by a production network for the vehicle registration in Arizona (cf. fig. 2), as described in the Economist (2000):

- Consumers can go online and renew their registrations in a transaction that takes an average of two minutes.

- The website is hosted and maintained by IBM, who receives and processes the data. IBM is paid US\$ 4 for this outsourced administrative procedure.

- Processing an online request costs US\$1.60. Therefore, the total costs for such a transaction amount to US\$ 5.60. 
- Compared with US\$ 6.60 for a counter transaction, the State of Arizona saves US\$ 1 per transaction. With $15 \%$ of renewals now being processed by this service, the motor vehicle department saves around US\$1.7m a year.

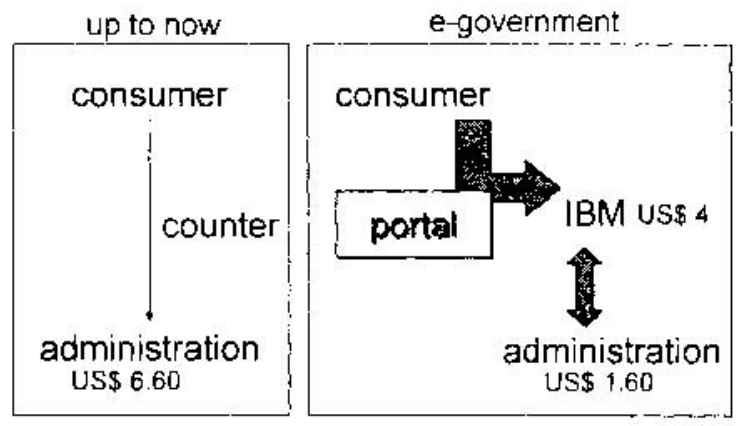

Figure 2. Vehicle registration in Arizona

As a matter of course, these figures cannot be transferred indiscriminately to circumstances in other countries. The interest lies primarily in the functionality of an electronic production network:

- Analysis of the single process steps.

- Division into process elements that might be outsourced and elements that have to remain within the agency. Economic criterion: efficiency through economies of scale and/or specific know-how; democratic criterion: warranty of political responsibility.

- Linking up processes with a third party for money (in this example: payment per transaction).

- Quality control carried out by the responsible agency.

- In addition, in case of more complex network structures, i.e. in case of many participants who are not all directly interlinked, the agency could assume a supervisory function.

\subsubsection{Electronic Public Services (ePS)}

Electronic Public Services (ePS) stand for the delivery of public services to benefit recipients, to private individuals, or to companies through local, regional, or national portals. Examples include electronic tax declaration and life event portals.

In the field of public services there is nearly no limit to imagination on how today's processes could be simplified due to e-government solutions. A well-known example is given by the electronic tax declaration, probably owing its popularity to a necessity for efficiency gains. In order to benefit from the possibilities offered by modem ICT, a system featuring as little media inconsistencies as possible has to be 
implemented, i.e. once entered, it should be possible to directly process a certain piece of information. For this reason, the best solution is the one that allows a tax payer to directly feed the data into the tax authority's browser, where the data is automatically processed. Ideally, in this way the assessment can be made on the same day, charging the tax payer immediately.

Each of these elements carries specific features and emphases, in such a way as to justify a theoretical separation. eDP primarily releases thoughts of a democraticpolitical nature, as it refers to decision-making processes in the politicaladministrative system. ePN focuses on the architecture of formal or informal networks and their impact. It can be organized in the background, i.e. without recognition effects on the citizens. On the contrary, ePS is a part of e-government that is visible to customers and citizens, and its conception is decisively coined by the demands and abilities of the benefit recipients. It is only in their wholeness that these three elements can be denoted as comprehensive e-government (cf. fig. 3).

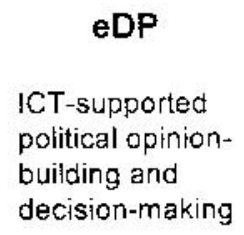

ePN

ICT-supported

co-ordination of

public-private

partnerships

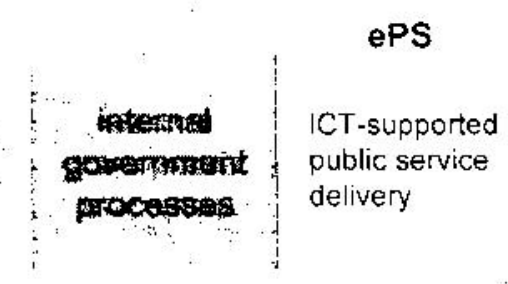

Figure 3. Process elements

\section{$2.2 \quad$ Culture}

The organizational culture comprises position and actions of individuals within the organization that make it work, including the performance of leaders individually and as a team, the agency's commitment to achieve common objectives, and the agency's commitment to training and support.

Culture describes informal processes. They cannot be controlled directly through deliberate intervention, but are influenced by environmental changes. Schedlerand 
Proeller (2000) define informal intervention as intervention through new behavioral patterns, which generally enter the organization as part of the administrative culture.

In particular, the administrative culture appears to be one of the biggest obstacles for an optimized e-government. This new organizational form entails an augmented openness towards stakeholders, which is not (yet) common to all administrative units. Reinermann (2000, p. 11) claims the necessity for substantial changes in the attitudes of politicians, administration, the public sector and society towards information technology. Features of this ,e-government culture“ in the politicaladministrative system are:

- Publicity of politics and administration: Comprehensive e-government gets very close to the ideal notion of a "transparent administration" by allowing processes to be monitored and reproduced over the Internet. The introduction of Political Information Systems (PIS), which make information for Parliamentarians available on the Internet, changes the way information is supplied. If, for example, the advantage in information of the Government over the Parliament is seen as an element of power, the principle of publicity bears a potential for slight shifts in power. As Grabow and Floeting (1999, p. 78) argue, this does not necessarily lead to better decisions e.g. when members of the Council overestimate their own judgement based on smattering.

- Customer orientation: Solutions which use the needs of the administration's customers as a guideline are based on the premises that the public sector a) has customers and $b$ ) has to accept their requirements.

- A culture of trust: Linking up processes means that departments and individuals, who have been able to fulfil their tasks isolated from others so far, are now collaborating. This requires an openness not only towards stakeholders, but also towards co-workers.

- Disposition to technology: Although the generation of those employees who refuse to personally make use of a computer is slowly retiring, a technologydisposed climate is an essential prerequisite for an e-government project to succeed.

\subsection{Relevant Management Techniques}

In this section, we discuss the contributions which three realms of business administration can make to the functioning of e-government: Knowledge Management, Process Redesign, and Quality Management.

\subsubsection{Knowledge Management}

In the public sector, there is a rising awareness of the importance of knowledge. Since management concepts were introduced into the public sector, knowledge has been recognized as a valuable resource (see e.g. Schedler and Proeller 2000). 
Knowledge can be categorized into explicit and implicit (tacit) knowledge (Nonaka and Takeuchi 1995). Explicit knowledge is available from files, library collections or data bases, whereas implicit knowledge is more difficult (and often impossible) to access: accumulated know how, experiences, creativity and skills all reside within individuals and make up the organization's knowledge capital. As no pecuniary value is attributed to this knowledge, it can easily be wasted. Particularly when reorganizing processes, the risk of losing implicit knowledge is high, as its carriers move on to new tasks and their experiences are no longer demanded (Gesellschaft für Informatik 2000).

The cohesion within the organization appears to be even more important. Knowledge which resides in individuals is of no use to an organization if these individuals are not integrated into a communication network that enables them to feed their knowledge into an organizational learning process, both targeted and in time (Lenk 2000). These communication networks are essential for ensuring the efficiency as well as the quality of processes that are new to public administration, e.g. e-procurement (cf. section 2.1.2). However, also "known" processes need to be supported by new networks as the physical distance between offices increases due to decentralization and parts of the processes are contracted out, only to mention a few examples of NPM-induced organizational changes.

\subsubsection{Process Redesign}

Business Process Redesign (BPR) aims at improving the productivity of an organization by altering the organization's processes. Rather than reformulating tasks, the efforts of redesign concentrate on the outcomes of the processes. Information technology is seen as an enabler for reorganization (Hammer and Champy 1993). IT-supported process redesign is not new to the public sector, but what is lacking is an integrated view of process redesign, led by a strong strategy that allows a consistent connection of different applications.

Besides cultural barriers, the difficulties in applying BPR to the public sector are founded in the nature of the political decision and production process (cf. section 2.1). Many administrative processes can be modeled on the sample of industrial production processes, leading to considerable cost-cuttings and quality improvements (Gesellschaft für Informatik 2000). However, more complex processes consist of case-based decision-making and are often limited to individuals. Due to their knowledge intensity, these processes cannot simply be formalized they must contain a margin for informal behavior. Lenk (1997) claims that a certain amount of ambiguity is functional for the survival of large organizations: "If opportunities for informal action are reduced too much, this ambiguity will be reduced at the expense of organizational innovation and flexibility".

Thaens, Bekkers and Duivenboden (1997, p.27) have observed the following pitfalls of applying BPR to the public sector: 
- While an improved productivity may be the ultimate goal of BPR in the private sector, redesigning policy processes cannot be geared solely to productivity. Public sector organizations are obliged to reckon with political, judiciary, economic, and professional boundaries.

- The complex regulatory environment of government agencies hampers the ideal situation of redesigning processes with a "clean slate ${ }^{, 73}$.

- The democratic principles of legal equality, legal security and the rule of law impede the application of creative strategies in redesigning policy processes.

- The primacy of politics could stand in the way of conducting strong management in the process of redesigning.

- BPR requires thinking in processes as opposed to thinking in terms of functional specialization of labor.

\subsubsection{Quality Management}

Quality has become a widely used term where the organization of public services is concerned. Traditionally, quality is equated with legitimacy and regularity in public sector organizations. Through the NPM, quality was extended to the customer orientation, enabling the service recipients to make demands on public services (Schedler and Proeller 2000). In the public sector, the following quality dimensions can be identified (Schedler and Proeller 2000, p. 65):

- Product-oriented quality: Differences in quality feature different product attributes. This type of quality includes the product itself as well as the way in which the product is supplied to the customer.

- Customer-oriented quality: Covers the aim of making an impact (generally a benefit) on the service recipients through service delivery. Includes customer satisfaction and an aspired change in customer behavior.

- Process-oriented quality: Indicates the measure of security of the processes (little errors) as well as their optimization (speed, efficiency). Includes questions regarding the legitimacy and regularity of service generation.

- Value-oriented quality: States whether a service is worth its price. Differences in quality are primarily shown through the costs/service ratio or the costs/effects ratio (efficiency).

- Political quality: The political bodies as contractors judge the quality of a service by its benefit for policy. One element is the objective benefit for society (e.g. better living standards, security), another the social benefit (e.g. social peace, coherence of a community).

The 'clean slate' approach demands that a business process be rebuilt from scratch, radically breaking with the past (Thaens, Bekkers and Duivenboden 1997). 
Therefore, a comprehensive quality management is concerned with the efficiency, the effectiveness, and the adequacy of public services. In order to assist public administrations to understand and use quality management techniques, the European Union developed a Common Assessment Framework (CAF), under which an ad hoc group of employees in an organization can conduct a critical assessment of their organization. The criteria are: leadership, policy and strategy, human resource management, external partnerships and internal resources, process and change management, customer/citizen-oriented results, employees results, impact on society, and key performance results (Hill and Klages 2000).

The interactions of the elements described above are shown in fig. 4. The process elements eDP, ePN, and ePS are organized around the internal government processes. The arrows symbolize the direction of the political decision-making and production process:

1. The decision-making process primarily evolves along the elements eDP internal processes - ePS. Here, the quality indicator is effectiveness.

2. The production process moves on the path ePN - internal processes - ePS. The quality of this process is best measured in terms of efficiency.

It should be mentioned that the model corresponds to our current organizational view, whereas the contextual variables are still missing - in fact, they represent one of the fields where we believe that further research into e-government needs to be done.

\section{e-government strategy}

e-government culture

eDP

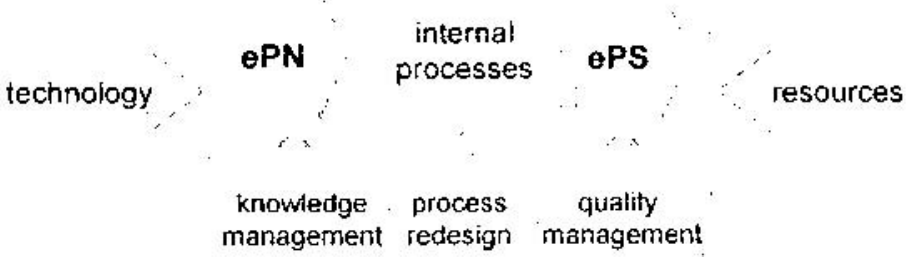

management techniques

Figure 4. E-government framework 


\section{EXPERIENCES WITH PUBLIC MANAGEMENT REFORMS}

Publications on modernizing the public sector are legion. Since the eighties, the New Public Management is the dominating international reform model, although it is regularly adjusted to national needs so that there is no such thing as a single international reform model (cf. section 1.2). The NPM is a new way of thinking the public sector - driven by theoretical frameworks that stem from new institutional economics and organizational theory. Its purpose is to cut the red tape or, in other words, break through bureaucracy (Barzelay 1992). In this context, researchers interested in organizational aspects have studied many reform projects with a focus on change management. Our own work (Schedler 1997, Schedler 1998) both in practice and theory leads to some important lessons that can be learned for the implementation of e-government in the public sector:

- Importance of administrative culture: Cultural change takes significantly longer than most project managers and champions of the NPM have expected. Our research demonstrates that implementation barriers are cultural to a high degree, and most often not instrumental or mechanistic. Therefore, a sensitive approach towards cultural change will be crucial for e-government, too.

- Political involvement: The more politicians are affected by the effects of the reforms, the earlier they should be included in the reform process. On the other hand, it came out clear in practice that it was a means to success to avoid political debates on the reform during the phase of designing the concept. egovernment seems to be a fairly technical and therefore apolitical reform process - ideological debates, of which there were many on NPM reforms, will not have to be expected here.

- Understanding the public sector: It was crucial for public management reform success that different disciplines worked together and shared their views from their perspectives, urging to understand each other. Most important, however, was a common understanding of the differences between the public and the private sector. The political and legal sphere in which the administration has to function and survive creates very particular patterns of behavior of its actors, which lead to a necessity for different reform strategies. Therefore, egovernment is much less a technical matter than e.g. e-commerce.

Altogether, it appears to be evident that the soil for e-government has been made fertile by reforms such as the NPM. Above all, the customer focus and its organizational consequences (e.g. one-stop shops, complaint management systems, life-event supplies) are an important predecessor for an e-government culture as described in section 2.2.

On the other hand, latest developments in countries such as Germany or Austria demonstrate that the introduction of e-government into the reform process can be a strong furthering factor for the reform in total. The reason for this effect, and the 
effect itself, have not been researched empirically yet, but an educated guess will lead to some important insights. First, the apolitical nature of e-government eases its introduction in comparison to the more ideological NPM. Second, a strategy-driven reform such as the NPM can be hindered by strategic debates on the benefit of such a reform, while no-one within the administration can stop the technological development that stands behind e-government, but happens isolated from it. Third, due to the necessity for a process redesign that is created by e-government, a real organizational change within the single administrative office has to take place, which leads to a faster impact of e-government in comparison to the NPM. Recapitulating, e-government can be interpreted as a reform element that supports the idea behind the NPM and, with its technological equipment, eases modernization as a whole.

\section{REFERENCES}

Barzelay, Michael (1992). Breaking Through Bureaucracy: A New Vision For Managing in Government. Berkeley, Los Angeles, Oxford: University of California Press.

Caldow, Janet (1999). The Quest for Electronic Government: A Defining Vision. Internet. Available: http://www.ieg.ibm.com/egovvison.pdf. 27 July 2000.

Economist (2000). "Survey Government and the Internet", The Economist: 24th June 2000.

Gesellschaft für Informatik (2000). Electronic Government als Schlüssel zur Modernisierung von Staat und Verwaltung, Bonn/Frankfurt.

Gisler, Michael (2001). Einführung in die Begriffswelt des eGovernment. In: eGovernment:

Eine Standortbestimmung. Gisler, Michael and Dieter Spahni. Bern, Stuttgart, Wien: Haupt. 13 - 30.

Grabow, Busso and Holger Floeting (1999). Wege zur telematischen Stadt. In:

Multimedia@Verwaltung. Jahrbuch Telekommunikation und Gesellschaft 1999. Kubicek, Herbert et al. Heidelberg: Hüthig. 75 - 87.

Hammer, Michael and James Champy (1993). Reengineering the Corporation: A Manifesto for Business Revolution. New York: Harper Business.

Hill, Hermann and Helmut Klages (2000). Good Governance und Qualitätsmanagement Europäische und internationale Entwicklungen. Speyerer Arbeitsheft Nr. 132, Speyer.

Hood, Christopher (1991). "A Public Management For All Seasons?” Public Administration 1991(69): 3-19.

Korac-Kakabadse, Andrew and Nada Korac-Kakabadse (1999). Information Technology's Impact on the Quality of Democracy. In: Reinventing Government in the Information Age: International Practice in IT-enabled public sector reform. Heeks, Richard. London: Routledge. 212 - 218.

Lenk, Klaus (1997). Business Process Reengineering in the Public Sector. In: Beyond BPR in Public Administration : Institutional Transformation in an Information Age. Taylor, J. M., Th. M. Snellen and A. Zuurmond. Amsterdam: IOS Press. 151 - 163.

Lenk, Klaus (2000). Ausserrechtliche Grundlagen für das Verwaltungsrecht in der Informationsgesellschaft: Zur Bedeutung von Information und Kommunikation in der Verwaltung. In: Verwaltungsrecht in der Informationsgesellschaft. Hoffmann-Riem, Wolfgang and Eberhard Schmidt-Assmann. Baden-Baden: Nomos. 
Nonaka, Ikujiro and Hirotaka Takeuchi (1995). The Knowledge-Creating Company : How Japanese Companies Create the Dynamics of Innovation. New York: Oxford University Press.

Ormond, Derry and Elke Löffler (1998). New Public Management - What to Take and What to Leave. III International Congress of CLAD on State and Public Administration Reform, Madrid, Spain.

Reinermann, Heinrich (2000). Der öffentliche Sektor im Internet: Veränderungen der Muster öffentlicher Verwaltungen. Speyer: Forschungsinstitut für öffentliche Verwaltung.

Schedler, Kuno (1997). The State of Public Management Reforms in Switzerland. In: Public Management and Administrative Reform in Western Europe. Kickert, Walter.

Cheltenham: Edward Elgar. 123 - 142.

Schedler, Kuno (1998). Blowing the Alphorn: Financial Management Reforms in Switzerland. In: Global Warning! Debating International Developments in New Public Financial Management. Olson, Olov, James Guthrie and Christopher Humphrey. Oslo: Cappelen Akademisk Forlag. 276 - 303.

Schedler, Kuno and Isabella Proeller (2000). New Public Management. Bern, Stuttgart, Wien: Haupt.

Schuh, Günther and Jochen Strack (1997). "Die virtuelle Fabrik - neue Flexibilität für dynamische Märkte.” Management \& Qualität / Special May: 12-13.

Tapscott, Don (1997). Growing Up Digital : The Rise of the Net Generation. New York: McGraw-Hill.

Thaens, Marcel, Victor Bekkers, et al. (1997). Business Process Redesign and Public Administration: A Perfect Match? In: Beyond BPR in Public Administration : Institutional Transformation in an Information Age. Taylor, J. M., Th. M. Snellen and A. Zuurmond. Amsterdam: IOS Press. 15 - 35. 